\title{
Outcome of Pediatric Acute Lymphoblastic Leukemia: Sixty Years of Progress
}

\author{
EWA DEMIDOWICZ*, MONIKA POGORZAŁA*, MONIKA ŁĘCKA, HANNA ŻOŁNOWSKA, \\ AGATA MARJAŃSKA, MAŁGORZATA KUBICKA, BEATA KURYŁO-RAFIŃSKA, KRZYSZTOF CZYŻEWSKI, \\ ROBERT DĘBSKI, ANDRZEJ KOŁTAN, MONIKA RICHERT-PRZYGOŃSKA and JAN STYCZYŃSKI
}

Department of Pediatric Hematology and Oncology, Collegium Medicum, Nicolaus Copernicus University Torun, Jurasz University Hospital, Bydgoszcz, Poland

\begin{abstract}
Background: A retrospective analysis was performed to investigate the survival outcomes in pediatric acute lymphoblastic leukemia (ALL) based on time period. We hypothesized that improvement has been obtained with the time-dependent therapeutic era and rise in the gross domestic product (GDP) and Human Development Index (HDI). Materials and Methods: Data from 710 children who were treated for ALL between 1958 and 2018 at a single pediatric center were analyzed for probability of 5-year overall survival ( $p O S)$, event-free survival ( $p E F S)$ and relapse risk $(p R R)$. Time periods were defined by the treatment protocols used in seven consecutive therapeutic eras. Results: Over the 60-year period analyzed, pOS increased from $1.2 \%$ to $90.7 \%$, pEFS from $1.2 \%$ to $86.6 \%$, and pRR decreased from $98.8 \%$ to $9.9 \%$ for patients treated in the past decade. Risk of mortality for patients who received chemotherapy and hematopoietic cell transplant was reduced to $9.9 \%$ in the recent era, however, no statistically significant survival difference was found between patients treated with stem cell transplant and those not. Conclusion: The therapeutic era, related to improved GDP and HDI, was a statistically significant predictor of increased OS from ALL.
\end{abstract}

Poland has a population of 38 million inhabitants, and every year, about 200-220 children (age $<18$ years) are diagnosed

\footnotetext{
*These Authors contributed equally to this study.

Correspondence to: Jan Styczynski, MD, Ph.D., Department of Pediatric Hematology and Oncology, Collegium Medicum, Nicolaus Copernicus University Torun, Antoni Jurasz University Hospital No. 1, ul. Sklodowskiej-Curie 9, 85-094 Bydgoszcz, Poland. Tel: +48 525854860, Fax: +48 525854087, e-mail: jstyczynski@cm.umk.pl
}

Key Words: Acute lymphoblastic leukemia, children, gross domestic product, Human Development Index, therapeutic era, survival. with acute lymphoblastic leukemia (ALL), the most frequent pediatric malignancy. History of the treatment of childhood ALL has become a paradigm for cancer cure (1). Clinical trials on ALL have successfully evolved over more than five decades in Europe, Asia and North America, and have contributed to the current cure rate of about $90 \%$ in childhood ALL in resource-rich countries (2). Few data are available on the progress of results of therapy in childhood ALL in less economically developed countries, especially when compared to the 1960s (3), an important aspect considering the number of Eastern European countries, including Poland, which underwent multi-aspect national transformation in the early 1990s.

In this study, we present results of therapy of 710 children diagnosed with ALL over a period of 60 years at a single center in Poland. We hypothesized that improvement in outcome might be related to the therapeutic era and rise in the gross domestic product (GDP) and Human Development Index (HDI).

\section{Patients and Methods}

Design of the study. All patients diagnosed and treated for ALL at a single pediatric center were included in retrospective analysis of outcomes of treatment, with respect to the therapeutic era, defined by time period when specific antileukemic treatment protocols were applied. The probability of 5-year overall survival (pOS) of children with ALL was also analyzed according to the changes in macroeconomic indicators GDP and HDI $(4,5)$ in Poland.

Patients. Between 1958 and 2018, a total of 710 patients aged under 18 years were diagnosed with ALL and treated at the Department of Pediatric Hematology and Oncology (Department of Pediatrics up to 1997) in Bydgoszcz, Poland. The follow-up was completed by mid 2019. The diagnosis of ALL was based on morphology of bone marrow, peripheral blood, and cerebrospinal fluid smears with the May-Grunwald-Giemsa method, and cytochemical analyses, employing the French-American-British classification. Immunophenotyping was performed from 1989 with the use of panels of monoclonal antibodies stained by immunohistochemical methods, followed by flow cytometry. 
Therapeutic protocols. With respect to time period and therapeutic protocols ('therapeutic era') used, patients were divided into seven groups according to therapy at time of diagnosis: Group I, 19581972: various therapies, 215 patients; group II, 1976-1983: St Jude Children's Research Hospital protocols V-VII $(6,7), 56$ patients; group III, 1983-1988: Berlin-Frankfurt-Munster ALL-BFM 76/79 protocols (8), 33 patients; group IV, 1988-1995: Nordic Society for Pediatric Hematology and Oncology (NOPHO) ALL-86 protocol (9), 81 patients; group V, 1995-2002: ALL-BFM-90 $(10,11)(96$ patients), and New York I/II protocols (12), 19 patients; group VI, 2002-2010: Intercontinental Cooperative ALL-IC-2002 protocol (13), 115 patients; and group VII, 2010-2018: ALL-IC-2009 protocol (13), 95 patients. Except for group I, for all other time periods, international treatment protocols were used. During the past two decades, some patients with high-risk disease and those with relapse qualified for hematopoietic cell transplantation (HCT) (14).

Statistical methods. The primary endpoint was the probability of OS. This variable, as well as probability of event-free survival (pEFS) and risk of relapse (RR) were calculated with the KaplanMeier method, and compared by log-rank test. An 'event' was defined as relapse or death. After adjusting for different risk groups within the protocols, the Cox regression model was used to calculate treatment outcomes for the seven therapeutic eras analyzed, and hazard ratios (HR) were calculated, with $95 \%$ confidence interval (95\% CI). SPSS 25 (IBM, Armonk, NY, USA) statistical package was used.

\section{Results}

Overall outcomes. Over the 60-year period analyzed, pOS increased from $1.2 \%$ to $90.7 \%(p<0.0001)$, pEFS from $1.2 \%$ to $86.6 \%(p<0.0001)$, and pRR decreased from $98.8 \%$ to $9.9 \%(p<0.0001)$ for patients treated in the past decade (Figure 1).

Outcome in different time periods. In group I, complete remission (CR1) was achieved by $111 / 215$ children, with a mean duration of 7 months. Mean OS was 0.8 years $(95 \%$ $\mathrm{CI}=0.7-1.0$ years), and probability of 5-year OS was $0.012 \pm 0.008$. In group II, CR1 was achieved by $51 / 56$ patients. Mean OS was 6.4 years $(95 \% \mathrm{CI}=3.4-9.3$ years $)$, however, relapse occurred in 41 cases, and only four children remained alive in long-term continuous CR1. In group III, CR1 was observed in 30/33 (90.9\%) children. Mean OS was 13.7 years (95\% CI=9.5-17.9 years). Twelve relapses occurred in this group, with only one patient surviving after relapse; the number of deaths in the analyzed group was 17 , thus 16 patients stayed in long-term remission. In group IV, CR1 was achieved in 71/81 children. Mean OS was 12.8 years (95\% CI=10.6-15 years), and 41 patients stayed in long-term remission, including four patients in CR2. In group V, 103/106 (97.2\%) children achieved CR. Mean OS was 11.2 years $(95 \% \mathrm{CI}=10.1-12.4)$. Relapse of disease occurred in $21(19.8 \%)$ patients, 30 patients died, and 76 patients stayed in long-term CR. In group VI, CR was
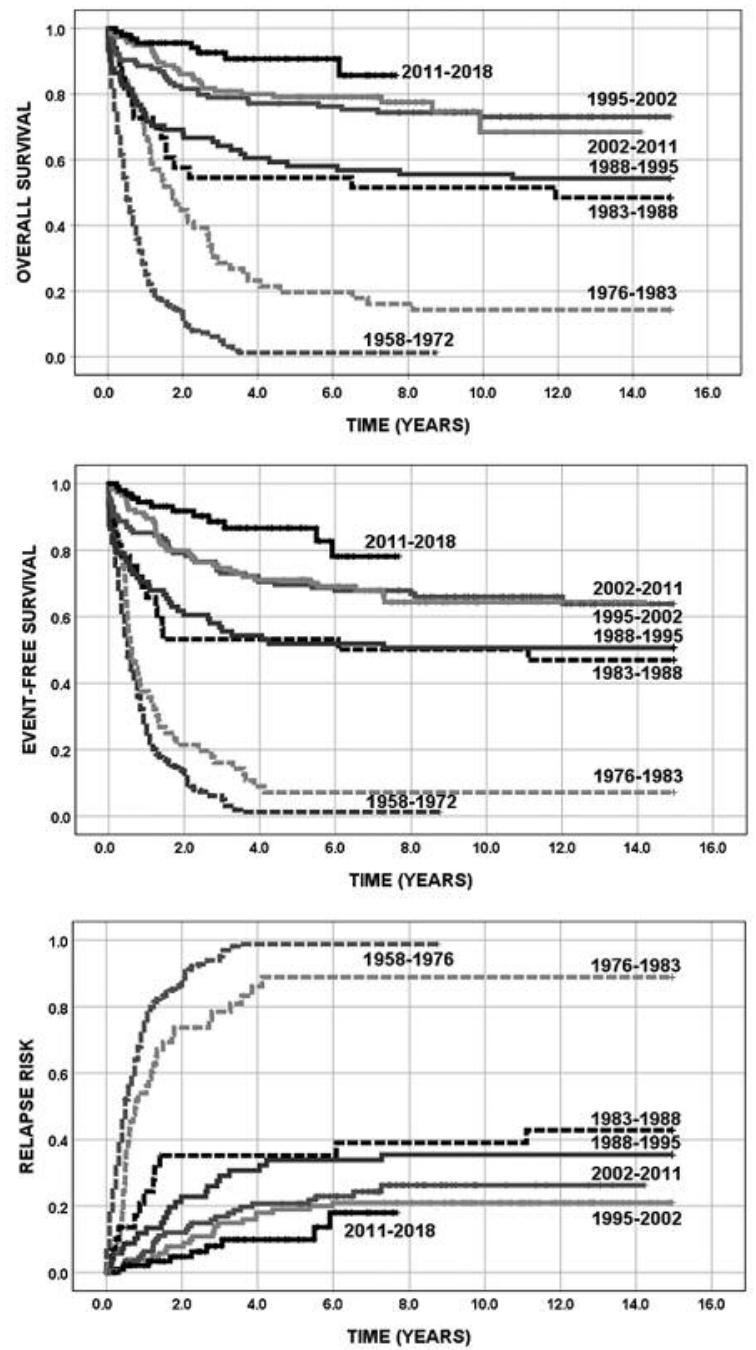

Figure 1. Treatment outcomes for children with acute lymphoblastic leukemia treated between 1958 and 2018.

achieved by $113 / 115(98.3 \%)$ patients. Mean OS was 7.4 years (95\% CI=6.8-7.8 years). Relapses occurred in 27 $(23.5 \%)$ children, deaths occurred in $26(22.6 \%)$, thus 87 patients stayed in long-term CR. In group VII, CR was achieved by $93 / 95(97.9 \%)$ patients. Mean OS was 4.1 years (95\% CI=2.7-6.5 years). Relapses occurred in nine $(9.5 \%)$ children, deaths occurred in eight $(8.4 \%)$, thus 87 patients stayed in long-term CR.

With respect to macroeconomic indicators, OS increased over time, corresponding to the growth of GDP of Poland (Figure 2).

Risk of treatment failure. After adjusting for different risk groups within the protocols, a Cox regression model was used to calculate treatment outcomes for the seven therapeutic eras 


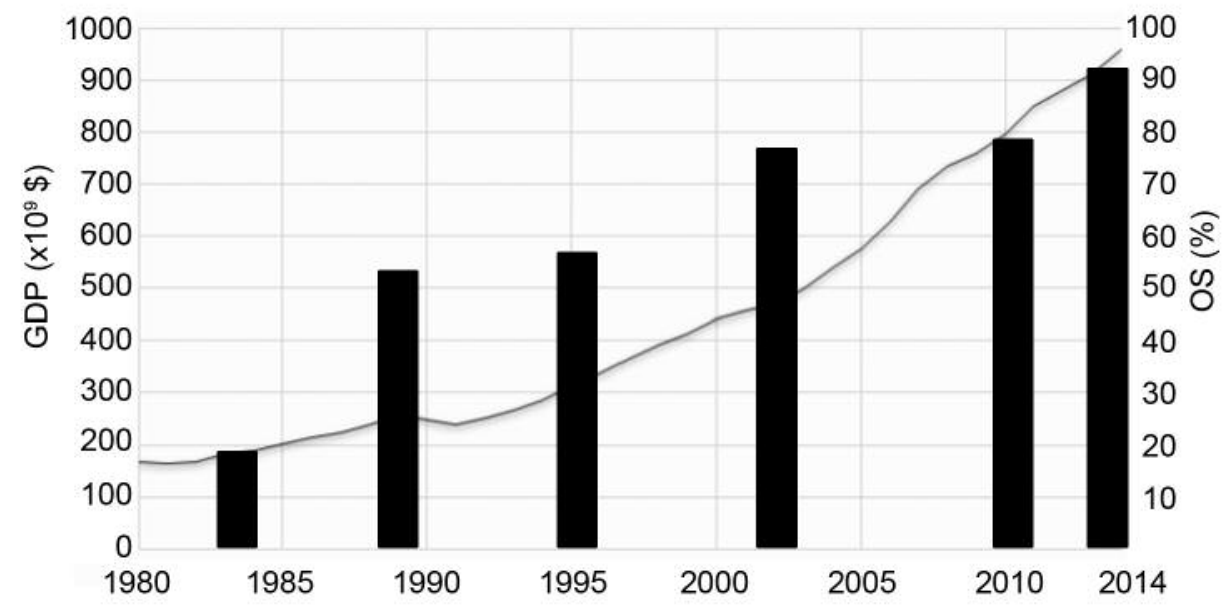

Figure 2. Overall survival (OS) and gross domestic product (GDP) for children with acute lymphoblastic leukemia in Poland. Primary axis: GDP (continuous line) provided in billions of international dollars as purchasing power parity, a way of measuring economic variables in different countries so that irrelevant exchange rate variations do not distort comparisons (1980-2014, https://en.wikipedia.org/wiki/Economy_of_Poland). Secondary axis: Probability of OS (black bars) of children with acute lymphoblastic leukemia.

Table I. Results of 5-year overall survival (pOS), event-free survival (pEFS) and relapse risk (pRR), with hazard ratio (HR) of death, event and relapse.

\begin{tabular}{|c|c|c|c|c|c|c|c|c|c|}
\hline \multirow[b]{2}{*}{ Therapeutic era } & \multicolumn{3}{|c|}{ 5-Year pOS } & \multicolumn{3}{|c|}{ 5-Year pEFS } & \multicolumn{3}{|c|}{ 5-Year pRR } \\
\hline & Probability & HR $(95 \%$ CI $)$ & $p$-Value & Probability & HR $(95 \%$ CI $)$ & $p$-Value & Probability & HR (95\% CI) & $p$-Value \\
\hline 2011-2018 & $0.907 \pm 0.034$ & 1 & & $0.866 \pm 0.041$ & 1 & & $0.099 \pm 0.036$ & 1 & \\
\hline $2002-2011$ & $0.791 \pm 0.038$ & $2.2(1.0-4.8)$ & 0.053 & $0.711 \pm 0.042$ & $2.1(1.1-4.1)$ & 0.022 & $0.207 \pm 0.039$ & $1.9(0.9-4.1)$ & 0.091 \\
\hline 1995-2002 & $0.779 \pm 0.043$ & $2.4(1.1-5.3)$ & 0.026 & $0.684 \pm 0.107$ & $2.2(1.1-4.2)$ & 0.016 & $0.194 \pm 0.044$ & $1.5(0.7-3.4)$ & 0.281 \\
\hline 1988-1995 & $0.580 \pm 0.055$ & $4.9(2.7-10)$ & $<0.0001$ & $0.519 \pm 0.056$ & $3.8(2.0-7.3)$ & $<0.0001$ & $0.338 \pm 0.069$ & $2.9(1.4-6.4)$ & 0.006 \\
\hline 1983-1988 & $0.545 \pm 0.087$ & $5.9(2.5-13)$ & $<0.0001$ & $0.532 \pm 0.088$ & $4.2(2.0-8.9)$ & $<0.0001$ & $0.390 \pm 0.092$ & $4.0(1.7-9.6)$ & 0.002 \\
\hline 1976-1983 & $0.196 \pm 0.053$ & $12.7(6.0-27)$ & $<0.0001$ & $0.074 \pm 0.034$ & $13.4(7.1-25)$ & $<0.0001$ & $0.888 \pm 0.049$ & $15.9(7.7-32)$ & $<0.0001$ \\
\hline 1958-1972 & $0.012 \pm 0.080$ & $30.8(15-62)$ & $<0.0001$ & $0.012 \pm 0.080$ & $18.5(10.3-33)$ & $<0.0001$ & $0.988 \pm 0.008$ & $29.9(15.2-58)$ & $<0.0001$ \\
\hline
\end{tabular}

CI: Confidence interval.

analyzed. Univariate analysis performed with respect to therapeutic era indicated that HRs for death, RR and risk of an event (relapse or death) decreased 30.8-, 24.5-, and 18.5fold, respectively, over the period analyzed (Table I).

Transplant outcome. From 2003, patients with relapse were also treated with HCT. Relative to patients who were treated with chemotherapy only, the risk of mortality for patients who received both chemotherapy and HCT was reduced to $9.9 \%$ in the most recent era. However, no statistically significant difference in survival was found between patients with relapse treated with HCT and those not [5-year pOS after HCT was 0.54 vs. 0.30 after chemotherapy only $(p=0.24)$ (data not shown)].

\section{Discussion}

Over the analyzed 60-year period, a steady improvement in the cure rate was observed in children with ALL admitted to our center. When compared to outcomes obtained in the USA $(6,7,12,15)$, Germany $(8,10,11)$ and Scandinavian countries (9), OS results of patients treated at our center were lower by about $15-20 \%$ up until 1995, however, although still worse afterward, the difference was no more than $10 \%$. The long-term survival rate increased from $1.2 \%$ in the 1960 s to $90 \%$ in the current era.

Lower treatment outcomes in our center, as compared to reports from American and German studies of 1975-1995, may have resulted from limited access to chemotherapeutic 
agents and insufficient access to adequate supportive therapy (16). Diagnosis of ALL might also have been delayed before 1990 because of limited diagnostic capabilities. Nevertheless, with the improvement of Poland's economical situation from the last decade of the 20th century, the outcomes of ALL have improved, and with the use of recent international protocols, the results are comparable to those of international groups (13). Still, we did not find any improvement to be associated with HCT, as was also observed in adolescent and young adults by others (17), although significant progress is being observed at our and other centers both in transplant and chemotherapy care $(14,18)$.

Despite Poland having one of the lowest values for GDP and HDI in Europe (5), Polish centers are able to strictly follow international protocols for children with ALL nowadays, and the results are even better, with 5-year EFS of $86.6 \%, 5$-year OS of $90.7 \%$, and RR 9.9\%. These results, with mean survival of 4.1 years, are better than the final results of the intercontinental trial ALL-IC-2002 which reached 5-year OS of $82 \%$, EFS of $74 \%$, and relapse rate of $19 \%$ (13).

In conclusion, lower GDP and HDI before 1990 affected all Polish pediatric hemato-oncology centers, including ours. However, current cooperation and participation of Polish centers within large international and intercontinental cooperative trials (ALL IC-2002 and ALL IC-2009) resulted in a cure rate of $90 \%$ and has created opportunities for even better future survival of pediatric patients with ALL with the use of modern treatment modalities, such as targeted or chimeric antigen receptor T-cell therapy $(19,20)$.

\section{Conflicts of Interest}

The Authors have no conflicts of interest to disclose in regard to this study.

\section{Authors' Contributions}

ED, MP: Concept/design, data collection, data analysis/ interpretation, writing article; MŁ, HŻ, AM, MK, BKR, KC, RD, AK, MPR: data collection, data analysis/interpretation, approval of article; JS: concept/design, data analysis/interpretation, critical revision of article, approval of article

\section{References}

1 Pui CH, Yang JJ, Bhakta N and Rodriguez-Galindo C: Global efforts toward the cure of childhood acute lymphoblastic leukaemia. Lancet Child Adolesc Health 2(6): 440-454, 2018. PMID: 30169285. DOI: 10.1016/S2352-4642(18)30066-X

2 Pui CH, Tang JY, Yang JJ, Chen SJ and Chen Z: International collaboration to save children with acute lymphoblastic leukemia. J Glob Oncol 5: 1-2, 2019. PMID: 31045474. DOI: 10.1200/JGO.19.00010

3 Ribeiro $\mathrm{R}$ and Pui $\mathrm{CH}$ : Treatment of acute lymphoblastic leukemia in low- and middle-income countries: challenges and opportunities. Leuk Lymphoma 49(3): 373-376, 2008. PMID: 18297510. DOI: $10.1080 / 10428190701882179$

4 Silla L, Fischer GB, Paz A, Daudt LE, Mitto I, Katz B, da Graca Grossini M, Bittencourt HN, Jochims A, Fogliatto L, Bittar CM, Friedrisch JR and Bittencourt RI: Patient socioeconomic status as a prognostic factor for allo-SCT. Bone Marrow Transplant 43(7): 571-577, 2009. PMID: 18978820. DOI: 10.1038/ bmt.2008.358

5 Giebel S, Labopin M, Ehninger G, Beelen D, Blaise D, Ganser A, Bacigalupo A, Czerw T, Holowiecki J, Fagundes EM, Nowara E, Frassoni F and Rocha V: Association of Human Development Index with rates and outcomes of hematopoietic stem cell transplantation for patients with acute leukemia. Blood 116(1): 122-128, 2010. DOI: 10.1182/blood-2010-01-266478

6 Simone J, Aur RJ, Hustu HO and Pinkel D: 'Total therapy' studies of acute lymphocytic leukemia in children. Current results and prospects for cure. Cancer 30(6): 1488-1494, 1972. PMID: 4509105. DOI: 10.1002/1097-0142(197212)30:6<1488::aid-cncr 2820300612>3.0.co;2-d

7 Rivera GK, Pinkel D, Simone JV, Hancock ML and Crist WM: Treatment of acute lymphoblastic leukemia. 30 Years' experience at St. Jude Children's Research Hospital. N Engl J Med 329(18): 1289-1295, 1993. DOI: 10.1056/NEJM19931028 3291801

8 Riehm H, Reiter A, Schrappe M, Berthold F, Dopfer R, Gerein V, Ludwig R, Ritter J, Stollmann B and Henze G: Corticosteroid-dependent reduction of leukocyte count in blood as a prognostic factor in acute lymphoblastic leukemia in childhood (Therapy Study ALL-BFM 83). Klin Padiatr 199(3): 151-160, 1987. DOI: $10.1055 / \mathrm{s}-2008-1026781$

9 Gustafsson G, Kreuger A, Clausen N, Garwicz S, Kristinsson J, Lie SO, Moe PJ, Perkkio M, Yssing M and Saarinen-Pihkala UM: Intensified treatment of acute childhood lymphoblastic leukaemia has improved prognosis, especially in non-high-risk patients: The Nordic experience of 2648 patients diagnosed between 1981 and 1996. Nordic Society of Paediatric Haematology and Oncology (NOPHO). Acta Paediatr 87(11): 1151-1161, 1998. PMID: 9846917.

10 Moricke A, Zimmermann M, Reiter A, Henze G, Schrauder A, Gadner H, Ludwig WD, Ritter J, Harbott J, Mann G, Klingebiel T, Zintl F, Niemeyer C, Kremens B, Niggli F, Niethammer D, Welte K, Stanulla M, Odenwald E, Riehm H and Schrappe M: Long-term results of five consecutive trials in childhood acute lymphoblastic leukemia performed by the ALL-BFM Study Group from 1981 to 2000. Leukemia 24(2): 265-284, 2010. PMID: 20010625. DOI: 10.1038/leu.2009.257

11 Schrappe M, Reiter A, Ludwig WD, Harbott J, Zimmermann M, Hiddemann W, Niemeyer C, Henze G, Feldges A, Zintl F, Kornhuber B, Ritter J, Welte K, Gadner H and Riehm H: Improved outcome in childhood acute lymphoblastic leukemia despite reduced use of anthracyclines and cranial radiotherapy: Results of trial ALL-BFM 90. German-Austrian-Swiss ALL-BFM Study Group. Blood 95(11): 3310-3322, 2000. PMID: 10828010.

12 Steinherz PG, Redner A, Steinherz L, Meyers P, Tan C and Heller $\mathrm{G}$ : Development of a new intensive therapy for acute lymphoblastic leukemia in children at increased risk of early relapse. The Memorial Sloan-Kettering-New York-II Protocol. Cancer 72(10): 3120-3130, 1993. PMID: 8221579. DOI: 10.1002/10970142(19931115)72:10<3120::aid-cncr2820721038>3.0.co;2-q

13 Stary J, Zimmermann M, Campbell M, Castillo L, Dibar E, Donska S, Gonzalez A, Izraeli S, Janic D, Jazbec J, Konja J, 
Kaiserova E, Kowalczyk J, Kovacs G, Li CK, Magyarosy E, Popa A, Stark B, Jabali Y, Trka J, Hrusak O, Riehm H, Masera G and Schrappe M: Intensive chemotherapy for childhood acute lymphoblastic leukemia: Results of the randomized intercontinental trial ALL IC-BFM 2002. J Clin Oncol 32(3): 174-184, 2014. DOI: 10.1200/JCO.2013.48.6522

14 Styczynski J, Debski R, Krenska A, Czyzewski K, Bartoszewicz N, Demidowicz E, Irga-Jaworska N, Drozynska E, Plonowski M, Krawczuk-Rybak M, Ociepa T, Urasiński T and Wysocki M: Role of HLA match on results of hematopoietic stem cell transplantations from unrelated donors in children with acute leukemia and bone marrow failure syndromes. Acta Haematol Pol 48: 48-53, 2017. DOI: 10.1016/j.achaem.2017.01.002

15 Pui CH, Pei D, Sandlund JT, Ribeiro RC, Rubnitz JE, Raimondi SC, Onciu M, Campana D, Kun LE, Jeha S, Cheng C, Howard SC, Metzger ML, Bhojwani D, Downing JR, Evans WE and Relling MV: Long-term results of St Jude Total Therapy Studies $11,12,13 \mathrm{a}, 13 \mathrm{~b}$, and 14 for childhood acute lymphoblastic leukemia. Leukemia 24(2): 371-382, 2010. PMID: 2820159 DOI: $10.1038 / \mathrm{leu} .2009 .252$

16 Boguslawska-Jaworska J: Pediatric hematology in Poland: Past and present. Pediatr Hematol Oncol 11(3): 243-250, 1994. PMID: 8060808.

17 Master S, Koshy N, Mansour R and Shi R: Effect of stem cell transplant on survival in adult patients with acute lymphoblastic leukemia: NCDB analysis. Anticancer Res 39(4): 1899-1906, 2019. PMID: 30952731. DOI: 10.21873/anticanres.13298
18 Zawitkowska J, Lejman M, Zaucha-Prazmo A, Drabko K, Plonowski M, Bulsa J, Romiszewski M, Mizia-Malarz A, Koltan A, Derwich K, Karolczyk G, Ociepa T, Cwiklinska M, Trelinska J, Owoc-Lempach J, Niedzwiecki M, Kiermasz A and Kowalczyk J: Grade 3 and 4 toxicity profiles during therapy of childhood acute lymphoblastic leukemia. In Vivo 33(4): 13331339, 2019. PMID: 31280227. DOI: 10.21873/invivo.11608

19 Okuhashi Y, Itoh $\mathrm{M}$ and Tohda S: Hedgehog stimulation suppresses clonogenicity and activates Notch signalling in Tlymphoblastic leukaemia Jurkat cells. Anticancer Res 37(9): 5005-5009, 2017. PMID: 28870926. DOI: 10.21873/anticanres. 11914

20 Park JH, Riviere I, Gonen M, Wang X, Senechal B, Curran KJ, Sauter C, Wang Y, Santomasso B, Mead E, Roshal M, Maslak P, Davila M, Brentjens RJ and Sadelain M: Long-term followup of CD19 CAR therapy in acute lymphoblastic leukemia. N Engl J Med 378(5): 449-459, 2018. PMID: 29385376. DOI: 10.1056/NEJMoa1709919
Received July 21, 2019

Revised August 4, 2019

Accepted August 7, 2019 